\title{
SJRM \\ Protective effect of zinc oxide nanoparticles on sperm parameters after freezing
}

\section{ARTICLE INFO}

\section{Article Type}

Original Research

\section{Authors \\ Elnaz Ashtari ${ }^{1}$, iD MSc \\ Fatemeh Siadat ${ }^{2}$, ID MD* \\ Niloofar Sodeifi ${ }^{3}$, MD \\ Sajjad Atashparvar ${ }^{4}$, MSc \\ ${ }^{1}$ MSc of cell and developmental biology, Department of Biology, College of Basic Science, Tehran Science and Research Branch, Islamic Azad University, Tehran, Iran. \\ 2 Assistant Professor of cell and developmental biology, Department of Biology, College of Basic Science, Islamic Azad University, Garmsa Branch, Garmsar, Iran. Department of Biology, College of Basic Science, Tehran Science and Research Branch, Islamic Azad University, Tehran, Iran \\ 3 Research Assistant Professor of Pathology, Department of Pathology, Reproductive Biomedicine Research Center, Royan Institute for Reproductive Biomedicine, ACECR, Tehran, Iran \\ ${ }^{4} \mathrm{MSc}$ of Medical Microbiology, Department of Medical Microbiology, Shahed University, and Tehran, Iran.}

*Corresponding Author Address: Daneshjoo St., University Square, Islamic Azad University, Garmsar Branch, Garmsar, Iran.Tehran, Iran.

Phone: +98 9125239489 \& +982334205009

Fsiadat2003@yahoo.com

\section{Article History}

Received: April 25, 2020

Accepted: May 27, 2020

e Published: January 13, 2021

\section{ABSTRACT}

Aims: Sperm freezing is most usable of method for the protection of reproductive performance in men who undergo gonadotoxic therapy such as chemotherapy or radiation treatment, or for the treatment of diseases such as infertility, autoimmune diseases and/or diabetes. Zinc oxide $(\mathrm{ZnO})$ nanoparticle has potent anticancer and antioxidant effects. The purpose of this study was to evaluate the protective effects of various concentrations of this nanoparticle on sperm freezing.

Methods: sixteen semen samples of normal human referred to Royan Center, were evaluated in 8 Fresh and Freeze and control groups. Groups included: Three fresh experimental groups were only exposed to $\mathrm{ZnO}$ nanoparticle with concentrations of 40, 80 and $100 \mathrm{ppm}$ and were analyzed half an hour later. Three freezing experimental groups were frozen after included concentrations of $\mathrm{ZnO}$ nanoparticle and thawed and analyzed half an hour later. Two control groups including control 1: were analyzed half an hour after exposure in culture and control 2: half an hour after freezing were thawed and analyzed. Count, morphology, motility, viability and $\mathrm{PH}$ of sperm were evaluated.

Findings: The results showed that $100 \mathrm{ppm}$ concentration of $\mathrm{ZnO}$ nanoparticle had the best protective effect on sperm $\mathrm{pH}$, survival, and motility in freezing process.

Conclusion: $\mathrm{ZnO}$ nanoparticle at a concentration of $100 \mathrm{ppm}$ can maintain $\mathrm{pH}$, motility and survival of sperm in the freezing process.

Keywords: ZnO nanoparticles; Sperm parameters; Human semen fluid; Sperm freezing. 


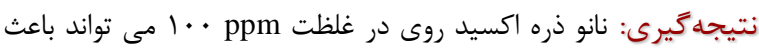

حفظ نسبى pH، تحرى و زنده مانى اسيرم در فرآيند انجماد كردد.

كليد وارّها: نانوذره اكسيد روى؛ پارامترهاى استرمى؛ مايع منى انسان؛

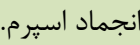

نتاريخ دريافت: 99/.

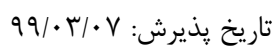

*نويسنده مسئول: سيده فاطمه سيادت

مقدمه

طبق تعريف سازمان جهانى بهداشت، نابارورى عدم توانايى زوجين در

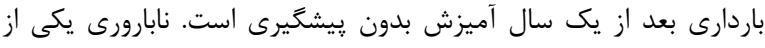

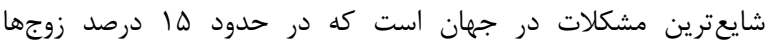

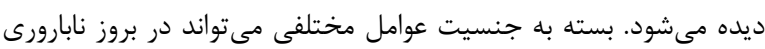

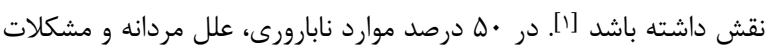

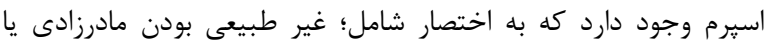

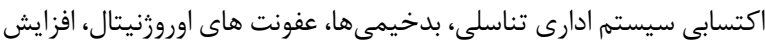

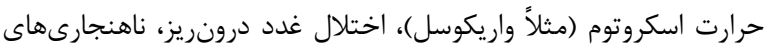

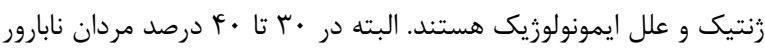

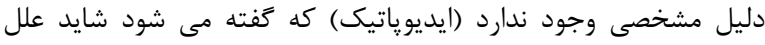
مختلفى مثل آلودگى محيط زيست، راديكالهاى آزاد اكسيرن (ROS)،

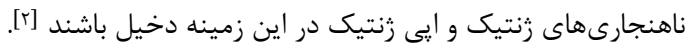

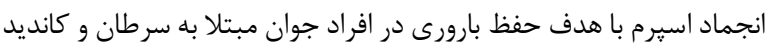

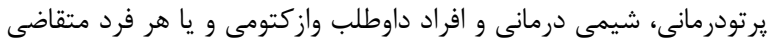

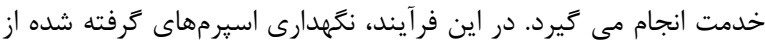

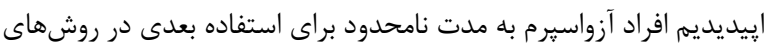

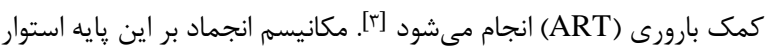

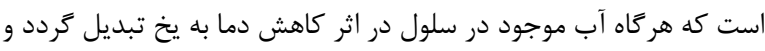

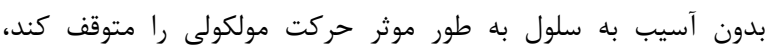

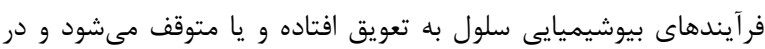

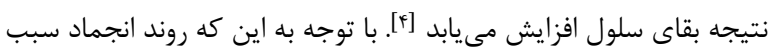

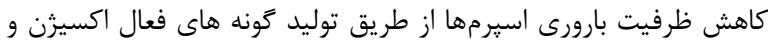

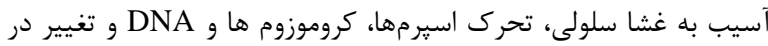

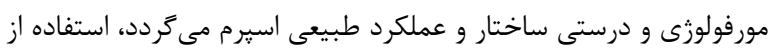

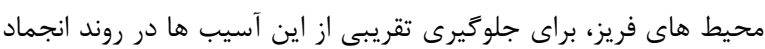

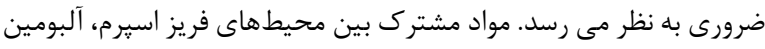

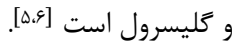

\section{اثر محافظتى نانو ذره اكسيد روى بر}

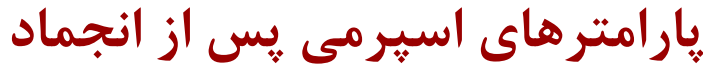

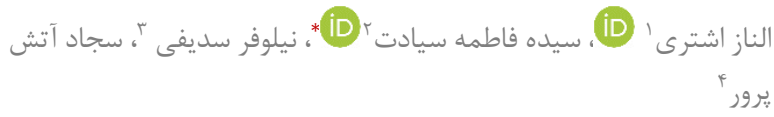
كارشناسى ارشد زيست شناسى سلولى تكوينى، گروه زيست شناسى،

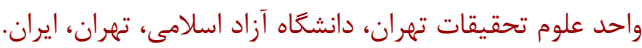

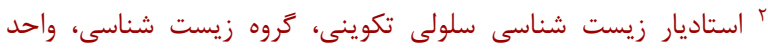

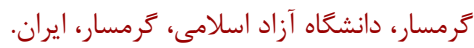

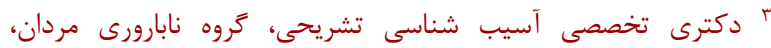

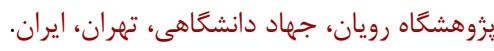

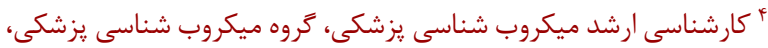
دانشعاه شاهد، تهران، ايران.

جكيده اهداف: انجماد اسرِم קركاربردترين روش براى محافظت عملكرد توليد

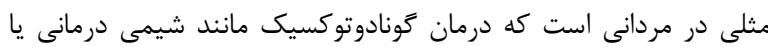

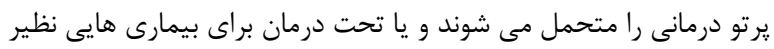

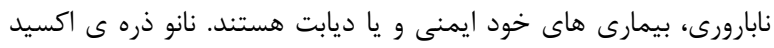

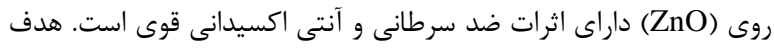

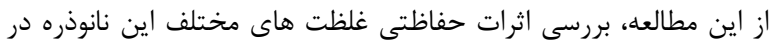
انجماد اسيرم مى باشد. روش ها: تعداد 19 نمونه مايع منى افراد نرمال مراجعه كننده به مركز

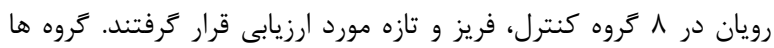

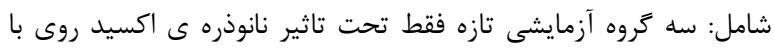

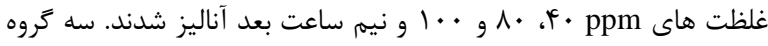

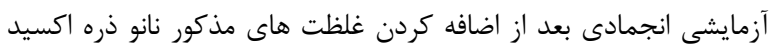

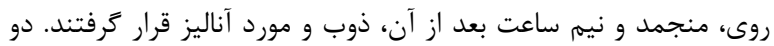

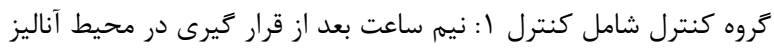

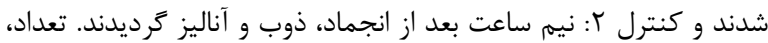

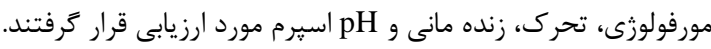

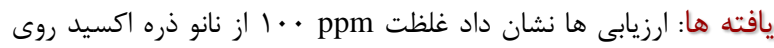
بهترين اثر حفاظتى را بر pH، زنده مانى و تحرك اسيرم در فرآيند انجماد

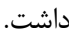




$$
\text { هر نمونه مايع منى به م قسمت به شرح زير تقسيم شد: }
$$

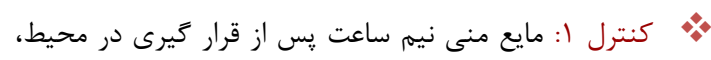
آناليز ترديد.

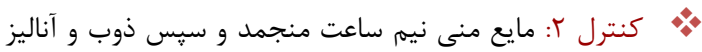

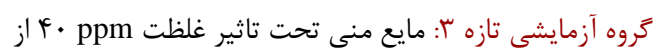
نانو ذره عى اكسيد روى قرار كرفت.

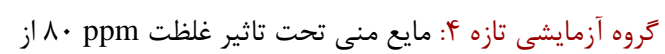
نانو ذره ى اكسيد روى قرار كرفت.

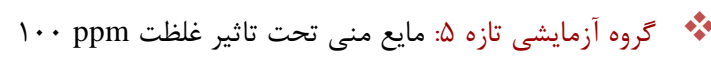

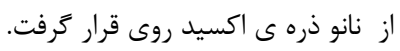

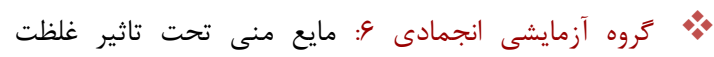

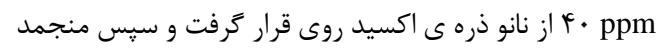
كرديد. هر خروه آزمايشى انجمادى V: كروهى كه مايع منى تحت تاثير

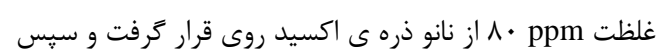
منجمد شد. كروه آزمايشى انجمادى م: خروهى كهد مايع منى تحت تاثير

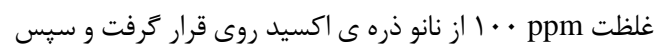
منجمد گرديد. در تمامى گروه ها نيم ساعت بعد از انجماد يا اضافه كردن نانو ذره، آناليز انجام شد. نانوذره ى اكسيد روى به صورت كلوئيد در اندازه ى ف نانومتر (شركت

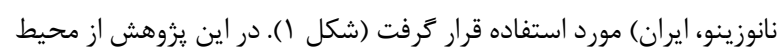

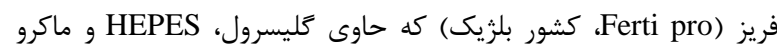

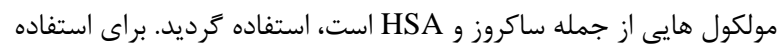

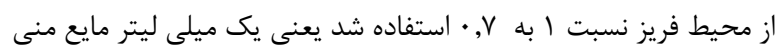

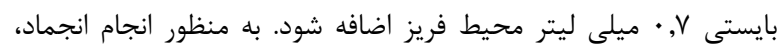

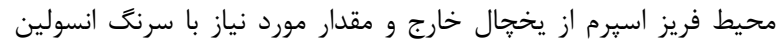

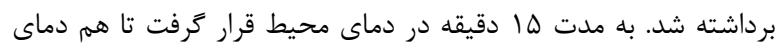

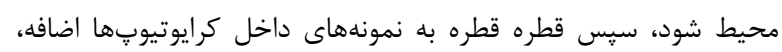

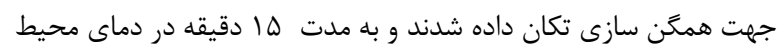

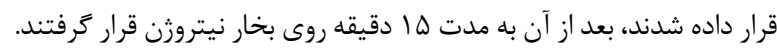

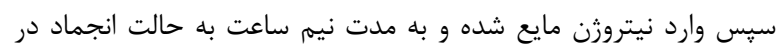

نانو ذره اكسيد روى به عنوان نانو ذره غير آلى جزء ير كاربردترين تركيبات

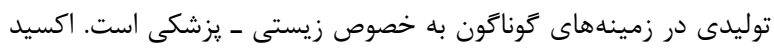

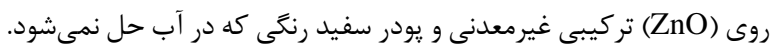

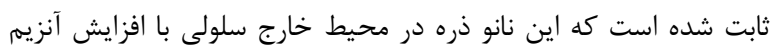

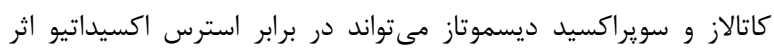

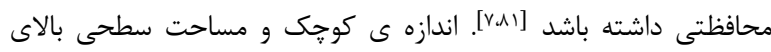

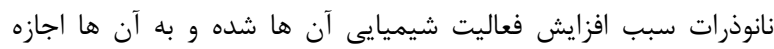

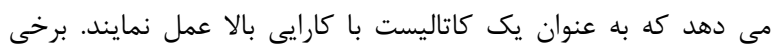

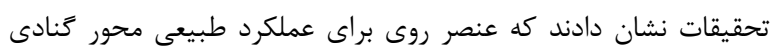

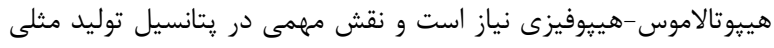

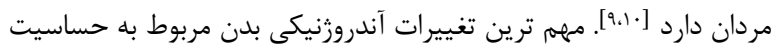

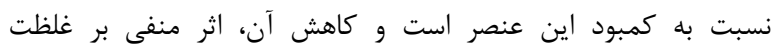

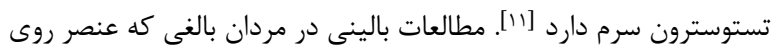

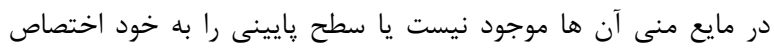

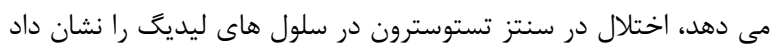

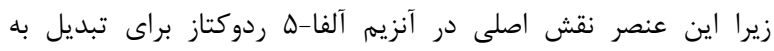

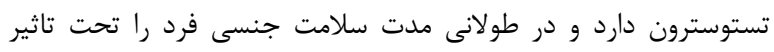

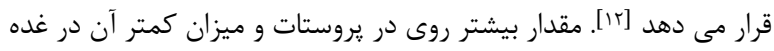

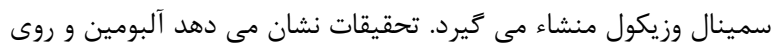

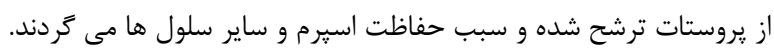

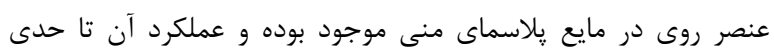

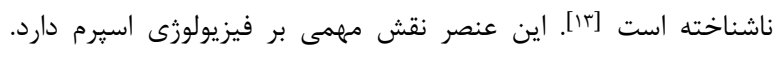

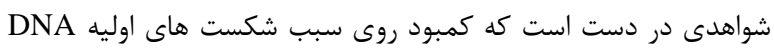

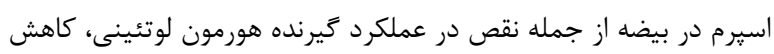

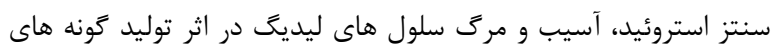

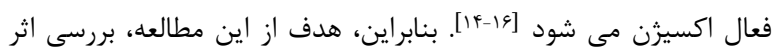

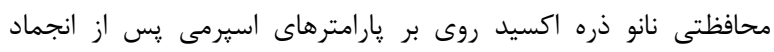
مى باشد.

\section{مواد و روش ها - ماد}

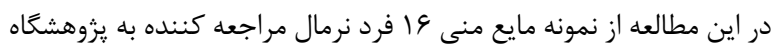

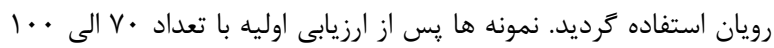

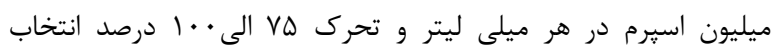

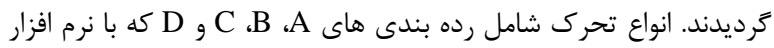

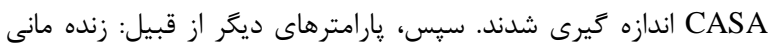
(Vitality)

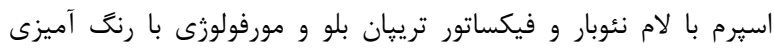
يإِانيكولا انجام شد. 


$$
\begin{aligned}
& \text { تعداد كل رديف هاى شمارش شده اسيرم ها در دو n } \\
& \text { طرف لام نئوبار }
\end{aligned}
$$

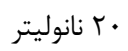

\section{$\mathrm{C}=(\mathrm{N} / \mathrm{n}) \times(1 / 20) \times$ dilution factor $\times 10^{6}$}

\section{pH روش بررسى}

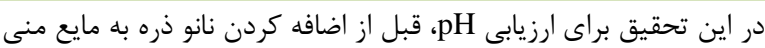

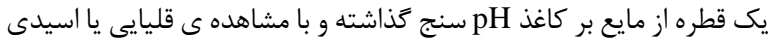

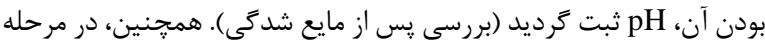

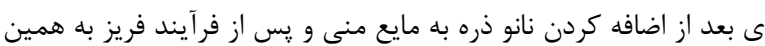

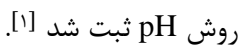

\section{روش رنك آميزى پإِانيكولا}

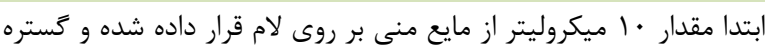

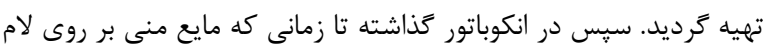

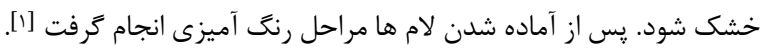

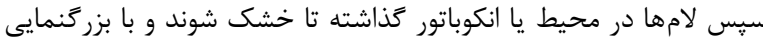

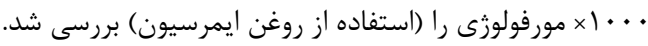

\section{روش بررسى تحرى}

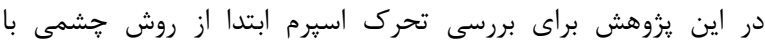

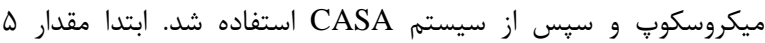

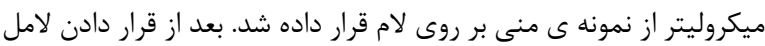

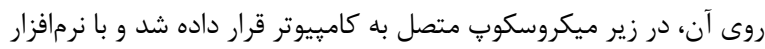
CASA

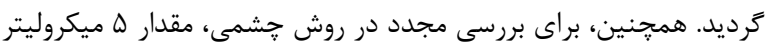

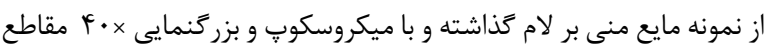

\section{تجزيه و تحليل آمارى}

اطلاعات به دست آمده از نمونه ها به وسيله نرم افزار

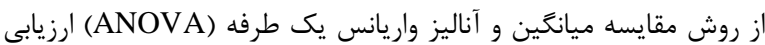

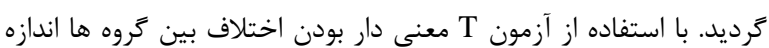

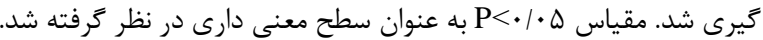

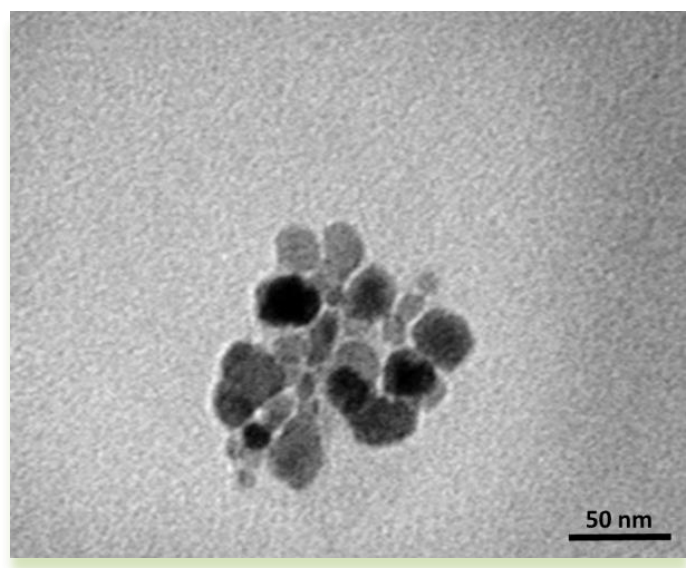

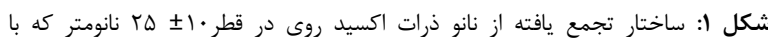

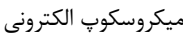

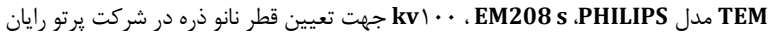
رستاك كرفته شد.

\section{روش بر رسى زنده مانى اسيرم ها}

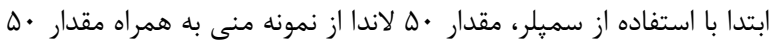

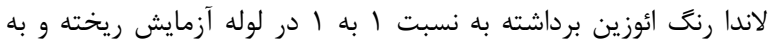

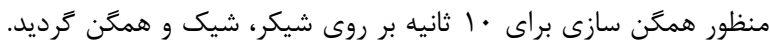

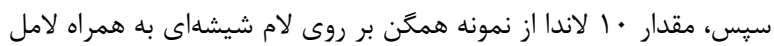

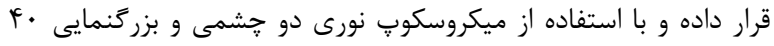

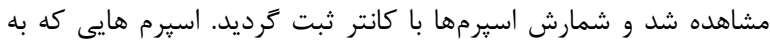

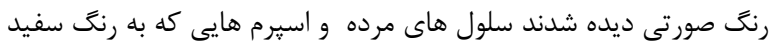

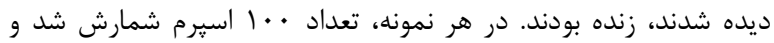
درصد اسيرم هاى زنده و مرده ثبت كرديدند.

\section{روش شمارش اسيرم ها با لام نئوبار}

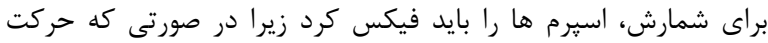

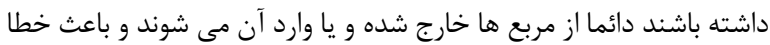

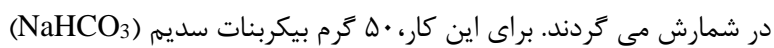

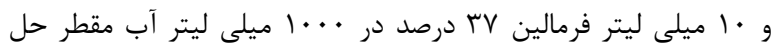

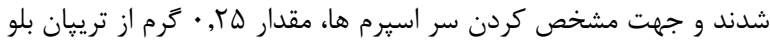

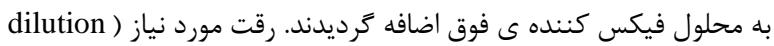

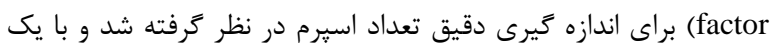

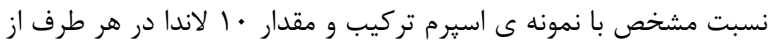

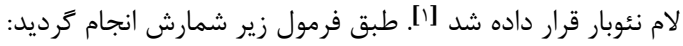

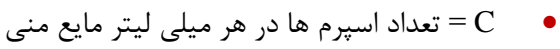
ت تعداد كل اسيرم هاى شمارش شده در دو طرف لام نئوبار 


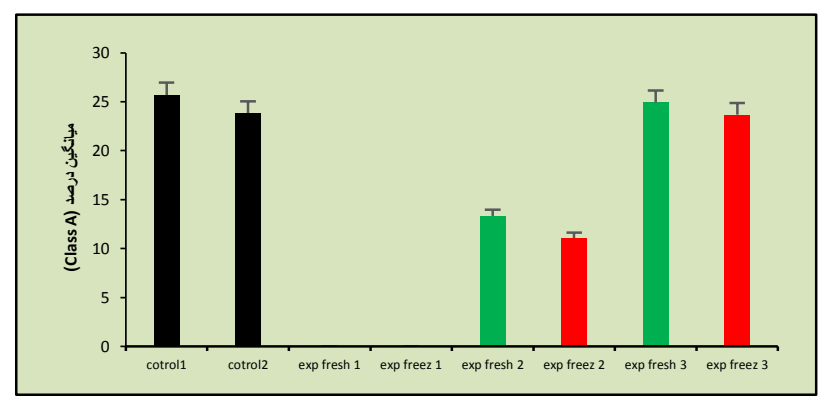

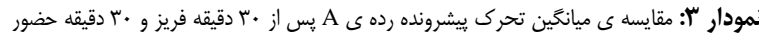

در محيط

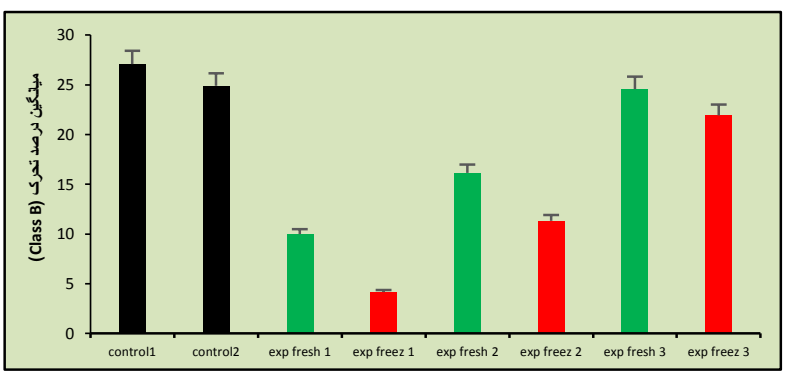

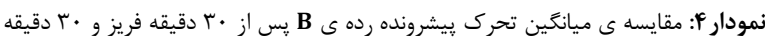
حضور در محيط نمانط

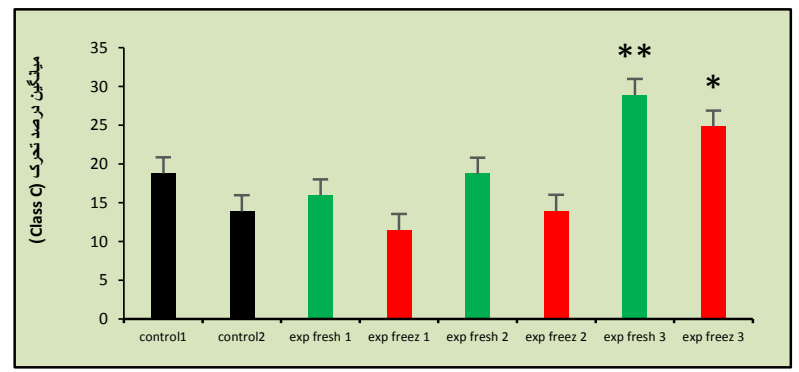

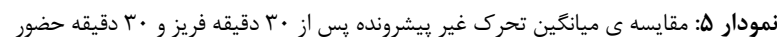

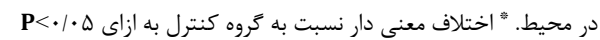

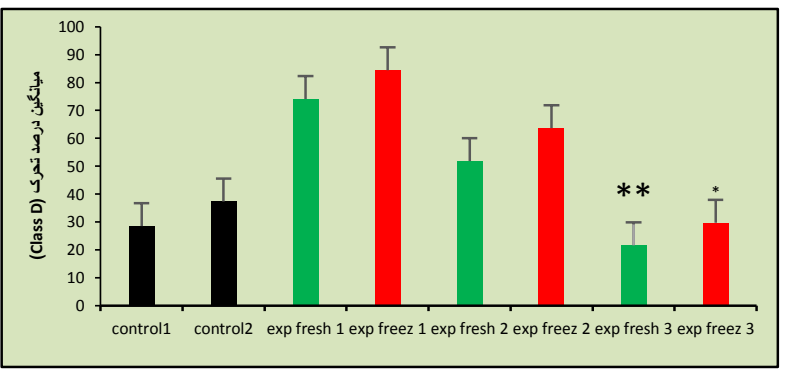

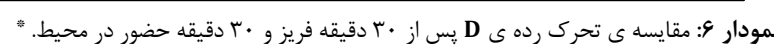

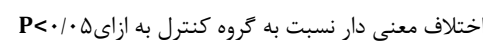

يافته ها

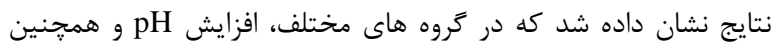

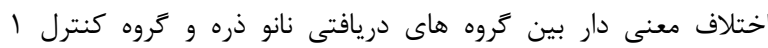

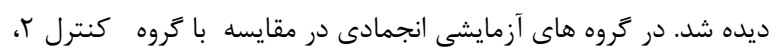

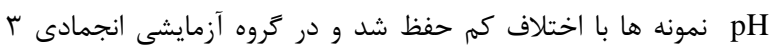

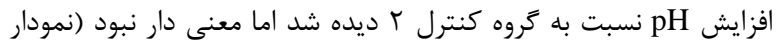

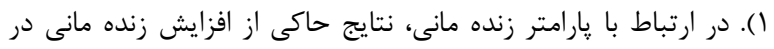

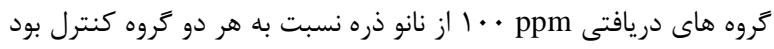

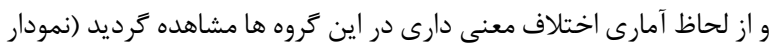

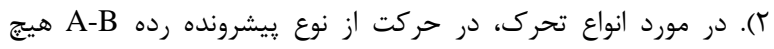

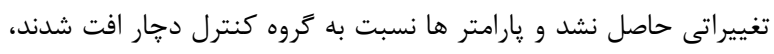

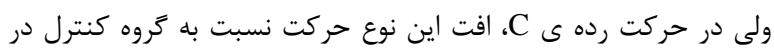

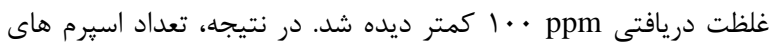

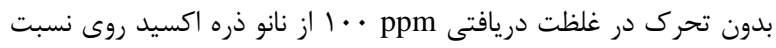

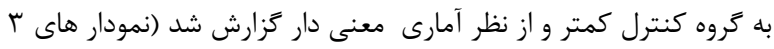

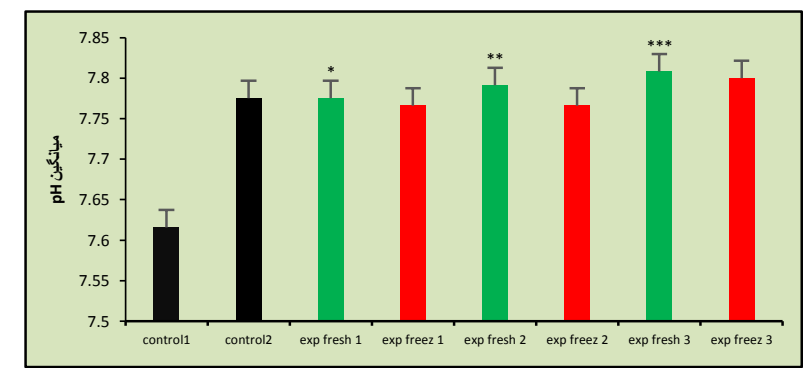

نمودار ا: مقايسه ى pH در كروه هاى مختلف ·r دقيقه بعد از فريز و ·r دقيقه حضور در

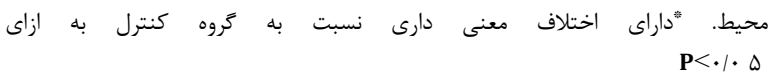

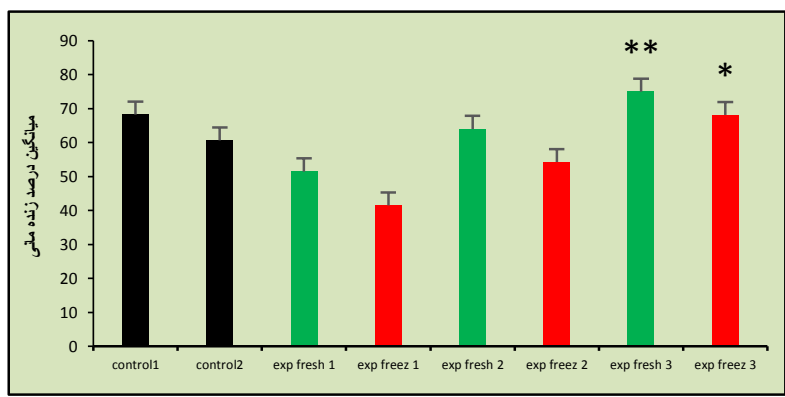

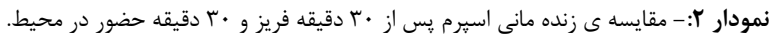

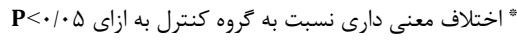


يزوهش با مطالعه ى Omu و همكاران (1 · r) كه ثابت كردند يارامتر هاى

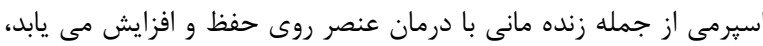

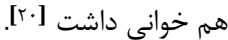

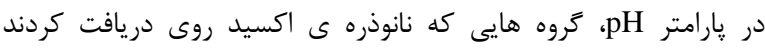

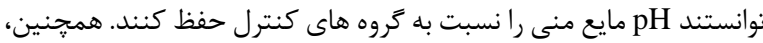

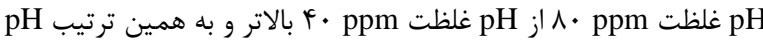

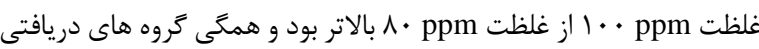

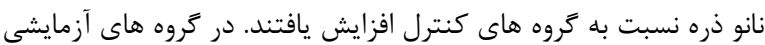

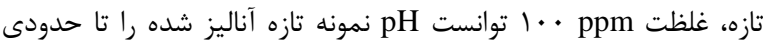

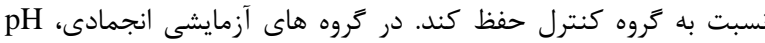

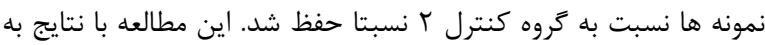

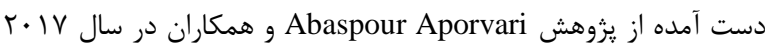

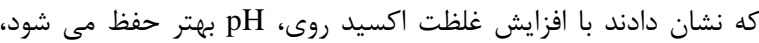

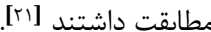
در اين يزوهش اثر حفاظتى و واكنش موثرى بر تعداد و مورفولوزى بعد از

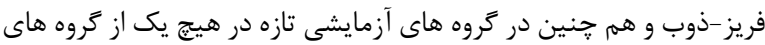
دريافتى نانو ذره اكسيد روى مشاهده نشد. در يزوهش Aporvari

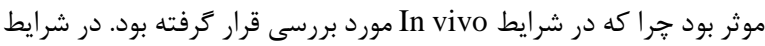
r Aporvari Abaspour Aporvari

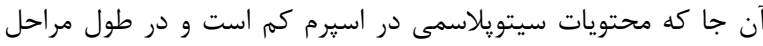

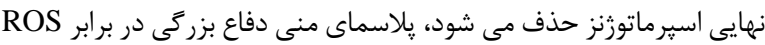
توسط آنزيمم مهار كننده ROS مانند سوير اكسيد ديسموتاز و كات ماتالاز است.

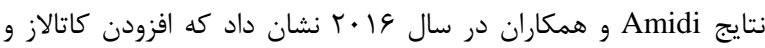

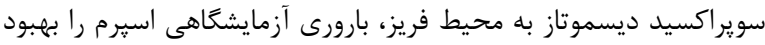

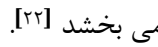
برخى محققان از عنصر روى تحت عنوان عنصر مرموز با مكانيسم هاى باى

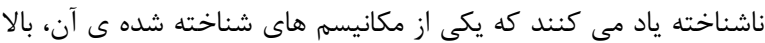

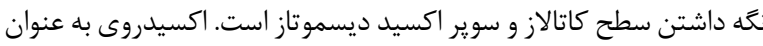

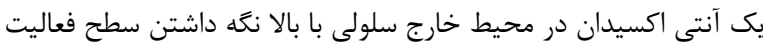

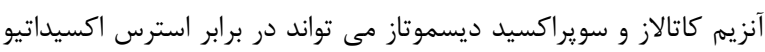

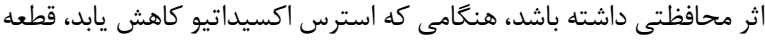

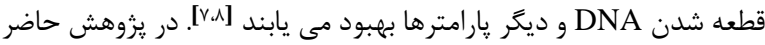

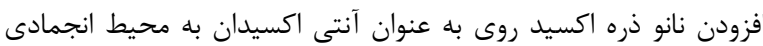

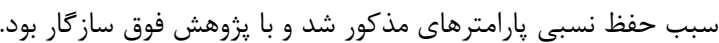

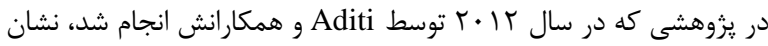

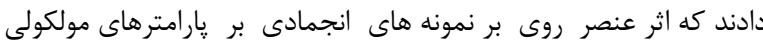

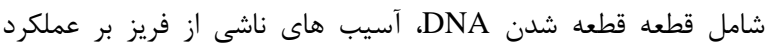

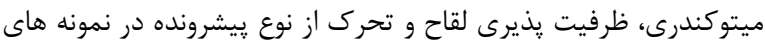

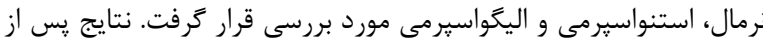

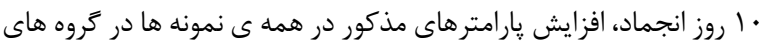

لازم به ذكر است كه با توجه به انجام آزمايش در شرايط In vitro، اثر

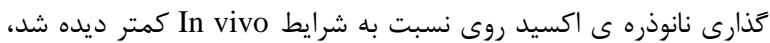

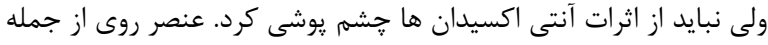

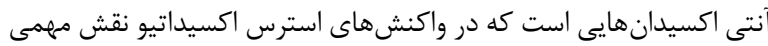

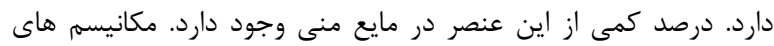

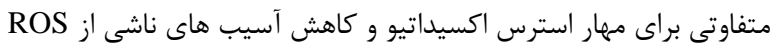
وجود دارد كه يكى از آن ها سيستم آنتى اكسيدان (Antioxidant) است.

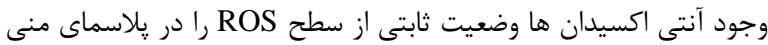

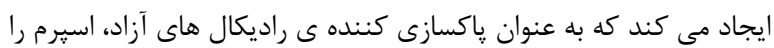

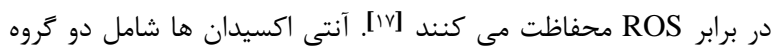
آنزيمى و غير آنزيمى هستند. انواع آنزيمى شامل: سوير اكسيد ديسموتاز

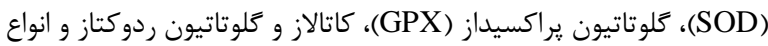

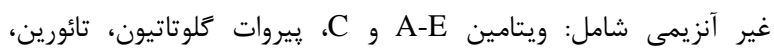

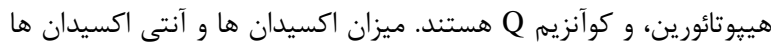

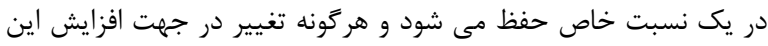

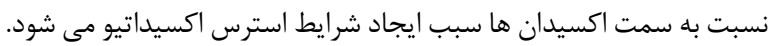

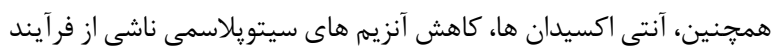

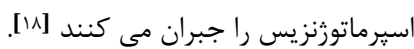

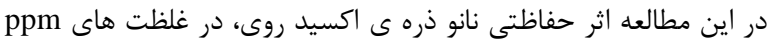

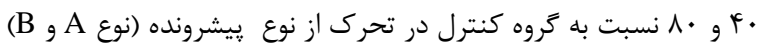

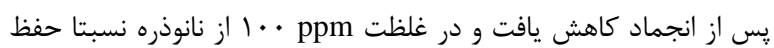

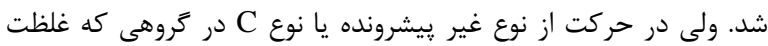

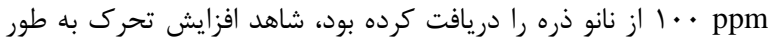

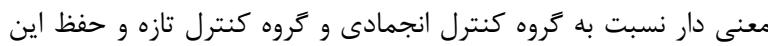

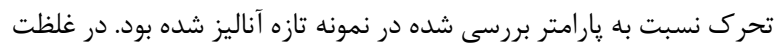

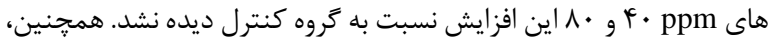

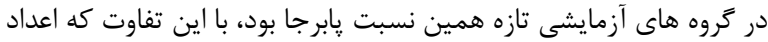

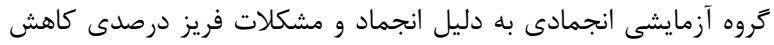

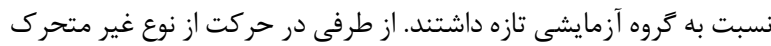

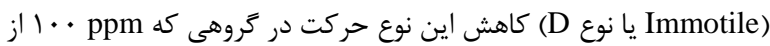

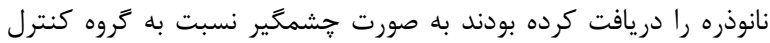

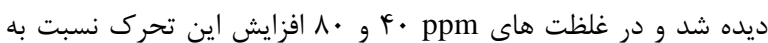

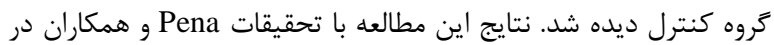

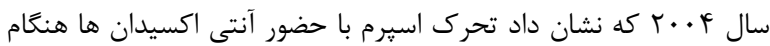

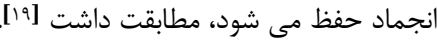

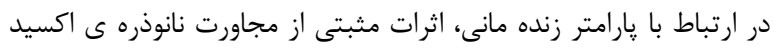

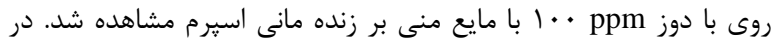

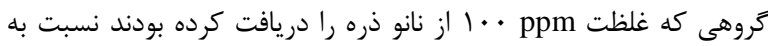

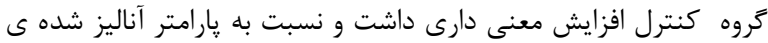

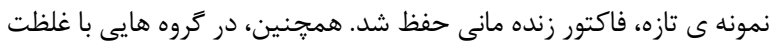

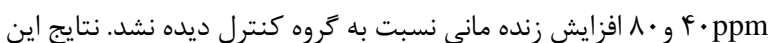




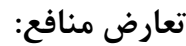 \\ در اين مطالعه تعارض منافع وجود نداشت.

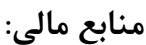 \\ توسط دانشخاه علوم تحقيقات تهران تامين شده است.
}

منابع

1. Organization WH. WHO laboratory manual for the examination and processing of human semen. 5th ed. Geneva: World Health Organization; 2010. 2010.

2. Lotti F, Maggi M. Sexual dysfunction and male infertility. Nature Reviews Urology. 2018;15(5):287-30.7

3. Suhag V, Sunita BS, Sarin A, Singh AK, Dashottar S. Fertility preservation in young patients with cancer. South Asian J Cancer. 2015;4(3):134-9.

4. Singh B, Mal G, Gautam SK, Mukesh M. Cryopreservation of oocytes and embryos. Advances in Animal Biotechnology: Springer; 2019. p. 97-108.

5. Nallella KP, Sharma RK, Allamaneni SS, Aziz

$\mathrm{N}$, Agarwal A. Cryopreservation of human spermatozoa: comparison of two cryopreservation methods and three cryoprotectants. Fertility and sterility. 2004;82(4):913.8-

6. Prins GS, Weidel L. A comparative study of buffer systems as cryoprotectants for human spermatozoa. Fertility and sterility. 1986;46(1):147-9.

7. Dawei A, Zhisheng W, Anguo Z. Protective effects of Nano-ZnO on the primary culture mice intestinal epithelial cells in in vitro against oxidative injury. World Journal of Agricultural Sciences. 2010;6(2):149-53.

8. Li Z, Yang R, Yu M, Bai F, Li C, Wang ZL. Cellular level biocompatibility and biosafety of ZnO nanowires. The Journal of Physical Chemistry C. 2008;112(51):20114-7.

9. Al-Ani NK, Al-Kawaz U, Saeed BT. Protective influence of zinc on reproductive parameters in male rat treated with cadmium. American Journal of Medicine and Medical Sciences. 2015;5(2):73-81.
دريافت كننده ى روى نسبت به كروه كنترل و هم جنين حفظ تقريبى

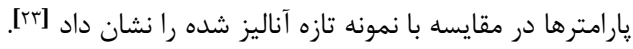

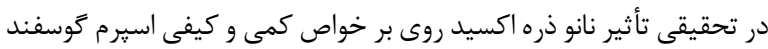

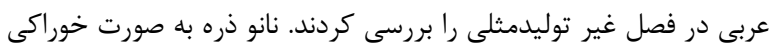

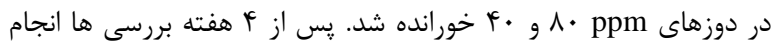

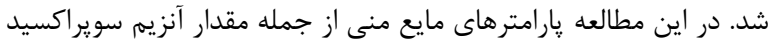

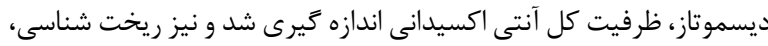

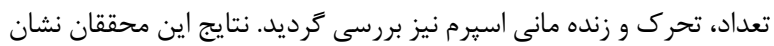

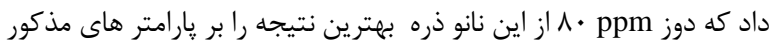

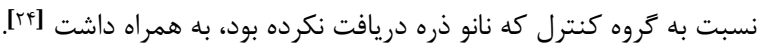

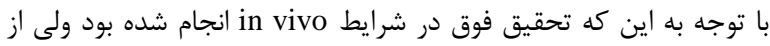

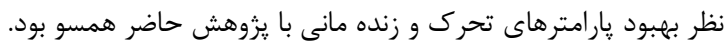

\section{نتيجه كيرى}

در اين مطالعه، يس از بررسى يارامترهاى اسيرمى شامل انواع تحرك، زنده

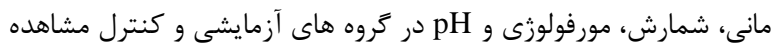

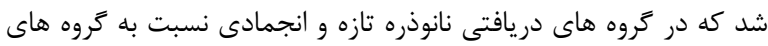

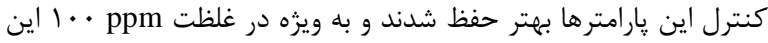

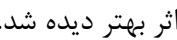

$$
\text { تشكر و قدردانى: }
$$

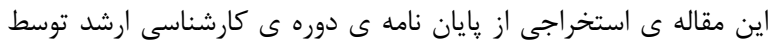

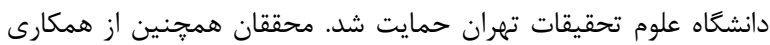

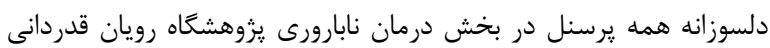
مى كنند.

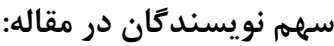
الناز اشترى (نويسنده ى اول)، نَارنده ى مقدمه/روش شناس/يزوهشكَر

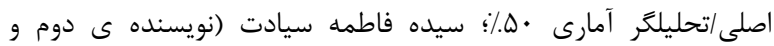

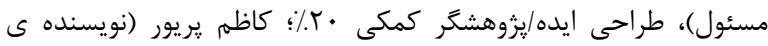

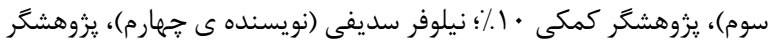

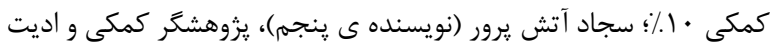

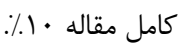


after cryopreservation of different fractions of the ejaculate. Anim Reprod Sci. 2003;78(12):85-98.

20. Omu A, Fatinikun $\mathrm{T}$, Mannazhath $\mathrm{N}$, Abraham S. Significance of simultaneous determination of serum and seminal plasma $\alpha$ tocopherol and retinol in infertile men by highperformance liquid chromatography. Andrologia. 1999;31(6):347-54.

21. Abaspour Aporvari M, Mamoei $M$, Tabatabaei Vakili S, Zareei M, Dadashpour Davachi N. The effect of oral administration of zinc oxide nanoparticles on quantitative and qualitative properties of arabic ram sperm and some antioxidant parameters of seminal plasma in the non-breeding season. Archives of Razi Institute. 2018;73(2):121-9.

22. Amidi F, Pazhohan A, Nashtaei MS, Khodarahmian M, Nekoonam S. The role of antioxidants in sperm freezing: a review. Cell and tissue banking. 2016;17(4):745-56.

23. Kotdawala AP, Kumar S, Salian SR, Thankachan P, Govindraj K, Kumar P, et al. Addition of zinc to human ejaculate prior to cryopreservation prevents freeze-thaw-induced DNA damage and preserves sperm function. Journal of assisted reproduction and genetics. 2012;29(12):1447-53.

24. Gharagozloo $\mathrm{P}$, Gutiérrez-Adán $\mathrm{A}$, Champroux A, Noblanc A, Kocer A, Calle A, et al. A novel antioxidant formulation designed to treat male infertility associated with oxidative stress: promising preclinical evidence from animal models. Human Reproduction. 2016;31(2):252-62.
10. Adedara IA, Abiola MA, Adegbosin AN, Odunewu AA, Farombi EO. Impact of binary waterborne mixtures of nickel and zinc on hypothalamic-pituitary-testicular axis in rats. Chemosphere. 2019;237:124501.

11. Elgazar V, Razanov V, Stoltenberg $M$, Hershfinkel M, Huleihel M, Nitzan YB ,et al. Zincregulating proteins, $\mathrm{ZnT}-1$, and metallothionein I/II are present in different cell populations in the mouse testis. Journal of Histochemistry \& Cytochemistry. 2005;53(7):905-12.

12. Fallah A, Mohammad-Hasani A, Colagar AH. Zinc is an essential element for male fertility: a review of $\mathrm{Zn}$ roles in men's health, germination, sperm quality, and fertilization. Journal of reproduction \& infertility. 2018;19(2):69-81.

13. Saleem TH, Okasha M, Ibrahim HM, ElHamd MA, Fayed HM, Hassan MH. Biochemical assessments of seminal plasma zinc, testisexpressed sequence 101 and free amino acids and their correlations with reproductive hormones in male infertility. Biological trace element research. 2020:1-14.

14. Abbasalipourkabir R, Moradi H, Zarei S, Asadi S, Salehzadeh A, Ghafourikhosroshahi A, et al. Toxicity of zinc oxide nanoparticles on adult male Wistar rats. Food and chemical toxicology. 2015;84:154-60.

15. Croxford TP, McCormick NH, Kelleher SL. Moderate zinc deficiency reduces testicular Zip6 and Zip10 abundance and impairs spermatogenesis in mice. The Journal of nutrition. 2011;141(3):359-65.

16. Yan M, Hardin K, Ho E. Differential response to zinc-induced apoptosis in benign prostate hyperplasia and prostate cancer cells. The Journal of nutritional biochemistry. 2010;21(8):687-94.

17. Halliwell B. Free radicals and antioxidants: updating a personal view. Nutrition reviews. 2012;70(5):257-65.

18. Agarwal A, Sharma RK, Sharma R, Assidi M, Abuzenadah AM, Alshahrani $S$, et al. Characterizing semen parameters and their association with reactive oxygen species in infertile men. Reproductive Biology and Endocrinology. 2014;12(1):33.

19. Peña FJ, Johannisson A, Wallgren $M$, Rodriguez Martinez H. Antioxidant supplementation in vitro improves boar sperm motility and mitochondrial membrane potential 